\title{
Serum LAMC2 enhances the prognostic value of a multi-parametric panel in non-small cell lung cancer
}

\author{
D Korbakis ${ }^{1,2}$, A Dimitromanolakis ${ }^{2}$, I Prassas ${ }^{1,3}$, G J Davis ${ }^{4}$, E Barber $^{5}, \mathrm{~K} \mathrm{~L} \mathrm{Reckamp}^{5}$, I Blasutig ${ }^{1,2}$ and \\ E P Diamandis ${ }^{\star}, 1,2,3$
}

${ }^{1}$ Department of Laboratory Medicine and Pathobiology, University of Toronto, Toronto, ON, Canada; ${ }^{2}$ Department of Clinical Biochemistry, University Health Network, Toronto, ON, Canada; ${ }^{3}$ Department of Pathology and Laboratory Medicine, Mount Sinai Hospital, Toronto, ON, Canada; ${ }^{4}$ Abbott Laboratories, Chicago, IL, USA and ${ }^{5}$ Department of Medical Oncology, City of Hope Comprehensive Cancer Center, Duarte, CA, USA

Background: Non-small cell lung cancer (NSCLC) lacks reliable serological biomarkers for predicting patients' survival and response to treatment. The present study examined the capability of serum LAMC2 and four known tumour markers for disease prognosis and patients' risk stratification.

Methods: LAMC2, CA 125, CEA, CYFRA 21-1 and SCC levels were retrospectively measured in sera obtained from 127 patients diagnosed with NSCLC by commercial immunoassays. Prognostic performance of the markers was compared with established clinical parameters and multivariate models were constructed to assess the prognostic complementarity of variables.

Results: LAMC2 showed significant prognostic ability for overall survival (hazards ratio: $1.607,95 \%$ confidence interval: 1.268-2.037, $P<0.0001)$ in the full cohort. LAMC2 and CYFRA 21-1 combination enhanced prognostic models based on common clinical parameters (c-index: 0.81 vs $0.72, P=0.00018$ ), further enabling stratification of patients into clear risk groups. A bootstrapbased cross-validation analysis was supportive of our findings. Combination of LAMC2 and CA 125 showed similar performance.

Conclusions: Our preliminary study proposes LAMC2 as a novel NSCLC prognostic factor. LAMC2 combined with CA 125 and CYFRA 21-1 could aid in clinical prediction of NSCLC patients' overall survival and inform clinical practice. Larger studies are necessary to unravel LAMC2's full potential as a new NSCLC biomarker.

Lung cancer is the second most frequently diagnosed cancer in the United States and the leading cause of cancer-related mortality in the western world (Jemal et al, 2011; Siegel et al, 2013). Lung cancer comprises a remarkably heterogeneous group of disease, the majority of which are of epithelial origin. From a histological point of view, lung carcinomas can be categorised into two main groups, the small cell lung cancer and the more common non-small cell lung cancer (NSCLC), which account for $\sim 85 \%$ of all lung cancer cases (Travis et al, 2004).

Despite intense research activity, the 5-year survival rate for NSCLC remains low (<15\%) (Siegel et al, 2013), partially because of the fact that one-third of patients are diagnosed with advanced stages of the disease (Govindan et al, 2008). Patients with early stage tumours have better survival rates (Flehinger et al, 1992), but even in the case of early stage disease there is high recurrence implying a more complex behaviour of the tumours (Singhal et al, 2005).

Absence of accurate prognostic tools impedes efforts for personalised care by not allowing for a proper assessment of the aggressiveness of each NSCLC. Despite the fact that several clinicopathological features-such as tumour staging (Mountain, 2000) - are routinely used as decision-making tools in NSCLC management, accurate prognosis remains an unfulfilled goal. To address this need, several serological markers have been tested for their ability to complement current prognostic modalities in 
NSCLC. Among them, cytokeratin 19 fragments (CYFRA 21-1), carcinoembryonic antigen (CEA), cancer antigen 125 (CA 125), squamous cell carcinoma antigen (SCC) and neuron-specific enolase (NSE) represent the five most widely investigated markers (Niklinski et al, 1992; Pujol et al, 1993; Margolis et al, 1994; Moro et al, 1995; Diez et al, 1996; Hirashima et al, 1998; Pujol et al, 2001; Vassilakopoulos et al, 2001; Hatzakis et al, 2002; Kulpa et al, 2002; Ando et al, 2003; Ferrigno et al, 2003; Molina et al, 2003; Barak et al, 2004; Muley et al, 2004; Okada et al, 2004; Arrieta et al, 2009). However, even if taken into consideration (mainly as disease monitoring markers), evidence for their prognostic value is still somewhat vague (Holdenrieder et al, 2010).

Laminins are a group of extracellular matrix proteins that exist as cross-shaped, heterotrimeric complexes of different isoforms of $\alpha, \beta$ and $\gamma$ chains (Timpl and Brown, 1994). They are important proteomic constituents of the basement membrane and are implicated in numerous biological processes, but predominantly epithelial morphogenesis (Timpl and Brown, 1994). So far, 16 members have been characterised biochemically (Hohenester and Yurchenco, 2013).

LAMC2 is a laminin gamma $(\gamma)$ chain $(\sim 130 \mathrm{kDa})$ encoded by the human gene $L A M C 2$, which is located in the chromosomal region 1q25-q31. LAMC2 is a unique part of the Laminin-332 trimer, which also includes laminin chains LAMA3 and LAMB3. The glycoprotein laminin-332 (formerly known as laminin-5) is specifically synthesised and secreted by epithelial cells and is involved in the cellular adhesion to basement membrane, as well as cell migration-especially during tumour invasion and metastasis (Rousselle et al, 1991; Fukushima et al, 1998).

There is ongoing research concerning the expression of the LAMC2 gene in various human malignancies (Soini et al, 1996; Sordat et al, 1998; Yamamoto et al, 2001; Koshikawa et al, 1999; Ono et al, 1999; Gasparoni et al, 2007)_including lung cancer (Maatta et al, 1999; Manda et al, 2000; Sathyanarayana et al, 2003; Ma et al, 2006; Takahashi et al, 2011; Masuda et al, 2012). All of these studies suggest that LAMC2 is elevated in most cancers and its overexpression is associated with poor prognosis and recurrence of the disease. However, very few studies have investigated the profile of LAMC2 serum levels in malignant conditions (Kuratomi et al, 2008), none for lung cancer in particular. Recently published data from our laboratory (Kosanam et al, 2013; Chan et al, 2014) proposed serum LAMC2 as a novel biomarker for pancreatic adenocarcinoma. Based on this initiative, we set the present study, aim of which was to investigate the utility of LAMC2 as a serum biomarker for NSCLC prognosis.

\section{MATERIALS AND METHODS}

Patients. A total of 127 patients diagnosed with different subtypes of NSCLC were included in this study. Clinicopathological parameters of the patients are listed in Table 1. Cancer stage was determined according to the American Joint Committee on Cancer Guidelines (6th and 7th edition) and the best available (clinical or pathological stage) was used. Blood samples were collected after diagnosis at the City of Hope Comprehensive Cancer Center (Duarte, CA, USA), between September 2008 and March 2012. Sample collection was approved by the City of Hope Institutional Review Board and included patient written informed consent. In brief, $8.5 \mathrm{ml}$ of peripheral blood was collected in a serum separation tube, was allowed to clot for $30 \mathrm{~min}$ at room temperature and then placed on ice. Within $2 \mathrm{~h}$ of blood draw, samples were centrifuged at $1100-1300 \mathrm{~g}$ for $10 \mathrm{~min}$ and separated. Serum was aliquoted and stored at $-80^{\circ} \mathrm{C}$ until analysis.

Immunoassay measurements. LAMC2 serum levels were measured using a commercially available enzyme-linked immunosorbent assay (USCN Life Science Inc., Wuhan, China). In line with the assay's
Table 1. Clinicopathological variables of the full patient cohort

\begin{tabular}{l|c|c|}
\hline Clinical parameters & $\mathbf{N}$ & $\%$ \\
\hline Number of patients & 127 & 100.0 \\
\hline Age_median (range) & $65(29-87)$ & - \\
\hline Sex & 62 & 48.8 \\
\hline Male & 65 & 51.2
\end{tabular}

Ethnicity group

\begin{tabular}{|c|c|c|}
\hline Hispanic & 15 & 11.8 \\
\hline Non-Hispanic & 112 & 88 \\
\hline White & 90 & 70 \\
\hline Black & 9 & 7.1 \\
\hline Asian Pacific Islander & 13 & 10 \\
\hline
\end{tabular}

\section{Tobacco use}

\begin{tabular}{|l|c|c}
\hline Never & 24 & 18.9 \\
Previous/current & 101 & 79.5 \\
Unknown & 2 & 1.6
\end{tabular}

\section{Histology}

Squamous

Adenocarcinoma

Large cell

Adenosquamous

Unclassified NSCLC

\begin{tabular}{l|l}
19 & 15.0
\end{tabular}

Stage

I

III

III

IIIB

IV

\section{Treatment}

\section{Surgery}

w/ Radiation

w/ Chemotherapy

w/ Both

No other treatment

No surgery

w/ Radiation

w/ Chemotherapy

w/ Both

No other treatment

\begin{tabular}{c|l}
85 & 66.9 \\
4 & 3.15
\end{tabular}

4
4

15

3.15
11.8

Status (at last contact)

\begin{tabular}{|l|l|l|}
\hline Deceased & 50 & 39.4 \\
Alive & 77 & 60.6 \\
\hline Abbreviations: NSCLC = non-small cell lung cancer; w/ = with
\end{tabular}

Abbreviations: NSCLC $=$ non-small cell lung cancer; $w /=$ with.

protocol, $100 \mu \mathrm{l}$ of serum samples (100-fold diluted in assay buffer diluent) and calibrators were loaded on pre-coated 96-well plates. Plates were incubated for $2 \mathrm{~h}$ at $37^{\circ} \mathrm{C}$, with gentle shaking. After washing, $100 \mu \mathrm{l}$ of detection reagent A were added and plates were incubated for $1 \mathrm{~h}$ at $37^{\circ} \mathrm{C}$ with gentle shaking. Wells were washed again and $100 \mu$ l of detection reagent $\mathrm{B}$ was added followed by incubation for $30 \mathrm{~min}$ at $37^{\circ} \mathrm{C}$ with gentle shaking. Following a final wash, $100 \mu \mathrm{l}$ of 3,3,5,5'-tetramethylbenzidine substrate solution was added and plates were incubated for $15 \mathrm{~min}$ at $37^{\circ} \mathrm{C}$ with gentle shaking. Stop solution $(50 \mu \mathrm{l})$ was added on top. Absorbance was measured with the Wallac EnVision 2103 Multilabel Reader (Perkin Elmer, Waltham, MA, USA) at $450 \mathrm{~nm}$, with a reference wavelength of $620 \mathrm{~nm}$. All samples were analysed in duplicate. The assay's withinrun and between-run precision was lower than $15 \%$ throughout the measurement range.

CA 125 (Ref\#2K45), CEA (Ref \#7K68), CYFRA 21-1 (Ref \#2P55) and SCC (Ref \#8D18) were measured using the clinical grade chemiluminescent microparticle immunoassays on ARCHITECT $i 2000$ system (Abbott Laboratories, 100 Abbott Park 
Road, Abbott Park, IL, USA), according to the manufacturers' protocol (Quinn, 2005). All samples were analysed in duplicate. The within-run and between-run precision of all chemiluminescent microparticle immunoassays was less than $10 \%$.

'The Cancer Genome Atlas' mRNA expression data in tissue samples. LAMC2 mRNA levels in NSCLC tissue samples were assessed by analysing RNA sequencing data from 'The Cancer Genome Atlas' portal (https://tcga-data.nci.nih.gov/tcga/, LUAD data set, downloaded December 2013). In total, 417 patients had information on both the mRNA expression at tumour tissue level and overall survival (OS) (median OS: 3.4 years; 104 patients had died through the follow-up). LAMC2 mRNA levels were dichotomised into high and low groups for the subsequent survival analysis.

Statistical analysis. Comparisons between groups were accomplished by analysis of variance or Pearson $\chi^{2}$ - (chi-square) tests. Overall survival was considered the primary analysis end pointmeasured from the time of diagnosis to the time of death. Univariate Cox proportional hazards models (Cox, 1972) were developed in order to investigate associations between different variables and OS. The examined variables included risk factors and clinicopathological parameters (such as age, smoking, histology, stage, surgery, chemotherapy and radiation therapy), as well as the continuous expression levels of all markers tested. All nonparametric estimates of the survival function were based on the Kaplan-Meier method (Kaplan and Meier, 1958) and differences between two Kaplan-Meier curves were evaluated by the log-rank test. Markers were assigned in two expression groups (high $v s$ low) based the assay manufacturers' suggested cut-offs (CA 125: $35 \mathrm{U} \mathrm{ml}^{-1}$, CEA: $5.00 \mathrm{ng} \mathrm{ml}^{-1}$, CYFRA 21-1: $2.08 \mathrm{ng} \mathrm{ml}^{-1}$ and SCC: $\left.1.5 \mathrm{ng} \mathrm{ml}^{-1}\right)$. Since LAMC2 lacks an optimal cut-off, the median value $\left(109.55 \mathrm{ng} \mathrm{ml}^{-1}\right)$ was chosen to dichotomise the population cohort.

Those variables demonstrating significance in a univariate analysis were included in subsequent multivariate modelling. Model selection was performed by employing a stepwise approach examining the inclusion or exclusion of each variable on every step. Akaike's information criterion (AIC) was used as a criterion to assess the goodness of fit of each model (Akaike, 1974). Univariate and multivariate Cox model regression coefficients were tested for significance using a Wald $\chi^{2}$-test. Concordance indices (c-index) were calculated in order to evaluate each model's performance in the survival data and were considered a measure of predictive ability (Harrell et al, 1982). The c-index is a natural extension of the ROC curve area as applied to survival analysis. A c-index value of 1 indicates perfect prognostic discrimination of a marker. Because of the lack of an independent validation set, a crossvalidation bootstrap approach $(N=1000)$ was employed to obtain a more realistic bias-corrected estimate of the model coefficients and the c-index, as implemented by the R package rms (available from http://biostat.mc.vanderbilt.edu/rms).

During statistical analyses, stage was analysed as a binary predictor (I/II/IIIA vs IIIB/IV) and marker levels were log transformed. Furthermore, all hypothesis testing was two-tailed, and $P$-values $<0.05$ were considered to indicate statistical significance. Statistical analysis was performed using $\mathrm{R}$ statistical software v 2.15.2 (available from http://www.Rproject.org) and SAS v9.2 (SAS Institute, Cary, NC, USA).

\section{RESULTS}

Quantitative analysis of five tumour markers in serum samples. Serum levels of the five markers (LAMC2, CA 125, CEA, CYFRA 21-1 and SCC) were assessed in the patient cohort using commercial enzyme-linked immunosorbent assays (Supplementary Table S1). CEA, CYFRA 21-1 and SCC were measured in a smaller group of patients $(N=113)$, due to unsystematic depletion of unrelated samples. To draw more reliable conclusions from our study, LAMC2 was first analysed on its own in the full cohort, followed by a comparative analysis with the rest of the markers in the common cohort.

Survival analysis in the full patient cohort. Follow-up time among the 127 patients varied from 0.13 to 8.41 years with a median of 1.12 years. Median OS was 2.1 years (95\% confidence interval (CI): $1.87-2.82$ ), as a result of 65 patients having an event at 2 years or presenting follow-up $>2$ years. Among the patients, 50 had died during the duration of the study (39\%). Median follow-up time among the remaining 77 patients was 1.16 years (interquartile range: $0.60-1.93$ ). Only 38 patients had undergone surgery and, therefore, we decided not to include relapse after surgery as an end point.

Association of LAMC2 and clinical parameters with patient OS using a univariate model in the full cohort. A univariate Cox proportional hazards regression analysis (Supplementary Table S2) revealed that among the seven clinical parameters (age, smoking, histology, stage, surgery, radiation and chemotherapy), only histology (adenocarcinoma vs squamous (hazards ratio (HR): $1.724,95 \%$ CI: $0.800-3.714)$ vs other (HR: 2.545, 95\% CI: $1.325-4.890), \quad P=0.0164)$ ), stage $\quad(\mathrm{HR}: 2.254, \quad 95 \%$ CI: $1.190-4.255, P=0.0121$ ) and surgery (HR: 2.362, 95\% CI: $1.176-4.744, P=0.0157)$ showed significant evidence of relation to OS. LAMC2 expression displayed significant prognostic value for OS (HR: 1.607, 95\% CI: 1.268-2.037, $P<0.0001$ ). According to Kaplan-Meier analysis, the median OS for patients with high levels of LAMC2 was 1.68 years as compared with 2.82 years for patients with low levels, indicating that LAMC2 is a marker of poor prognosis (Supplementary Figure S1). At a follow-up of 2 years, survival of patients with high vs low LAMC2 levels was 32\% vs $79 \%$, respectively, as compared with an OS of $54 \%$.

The association of LAMC2 with the seven clinicopathogical parameters was also examined (Student $t$-test or linear model, where appropriate) (Supplementary Table S3). According to results, LAMC2 was found to correlate (coefficient $=0.8807$, $P=0.0014$ ) only with advanced disease stage (IIIB/IV).

Association of five tumour markers and clinical parameters with patient OS using a univariate model in the common cohort. Univariate Cox Proportional Hazards regression analysis of the common cohort revealed that among the seven clinical parameters (age, smoking, histology, stage, surgery, radiation and chemotherapy), only histology (adenocarcinoma vs squamous (HR: 1.852, 95\% CI: 0.776-4.422) vs other (HR: 3.449, 95\% CI: 1.677-7.093), $P=0.0032)$ and stage (HR: $2.415,95 \%$ CI: $1.149-5.076, P=0.020$ ) showed significant evidence of relation to OS. Surgery appeared to be borderline non-significant (HR: 2.132, 95\% CI: 0.980-4.637, $P=0.0563$ ) (Table 2).

LAMC2 expression displayed significant prognostic value for OS (HR: $1.578,95 \%$ CI: $1.207-2.063, P=0.0009)$. Additionally, CA 125 (HR: $1.339,95 \%$ CI: $1.151-1.557, P=0.0002$ ) and CYFRA 21-1 (HR: 1.492 , 95\% CI: $1.239-1.798, P<0.0001)$ were also related to poor OS. The rest of the markers showed insignificant prognostic ability in relation to OS.

According to Kaplan-Meier analysis, differences in the median OS between high and low LAMC2 expression groups remained significant $(P=0.0002)$ (Figure $1 \mathrm{~A})$. Similarly, median OS for patients with high CYFRA 21-1 levels was 1.33 years compared with 2.74 years for the ones with low levels $(P=0.0007)$ (Figure 1B). On the other hand, median OS for patients with high levels of CA 125 did not differ from the ones that had low levels (2.30 years vs 2.56 years, $P=0.1007)$. Finally, the difference in median OS between high vs low CEA expression groups was marginally significant $(P=0.0378)$ (Figure 1C). 
Table 2. Univariate Cox model for OS in the common cohort

\begin{tabular}{|c|c|c|c|c|}
\hline Parameters & Risk group & HR & $95 \% \mathrm{Cl}$ & $P$-value ${ }^{a}$ \\
\hline Age & - & 1.011 & $0.988-1.035$ & 0.3444 \\
\hline Smoking & $\begin{array}{c}\text { Previous/ } \\
\text { current }\end{array}$ & 1.079 & $0.442-2.632$ & 0.8672 \\
\hline \multirow[t]{3}{*}{ Histology ${ }^{b}$} & & & & 0.0032 \\
\hline & Squamous & 1.852 & $0.776-4.422$ & \\
\hline & Other & 3.449 & $1.677-7.093$ & \\
\hline Stage & IIIB-IV & 2.415 & $1.149-5.076$ & 0.02 \\
\hline Surgery & No & 2.132 & $0.980-4.637$ & 0.0563 \\
\hline Radiation therapy & No & 0.817 & $0.439-1.521$ & 0.5236 \\
\hline Chemotherapy & No & 0.956 & $0.438-2.085$ & 0.9101 \\
\hline LAMC2 $^{c}$ & - & 1.578 & $1.207-2.063$ & 0.0009 \\
\hline CA $125^{c}$ & - & 1.339 & $1.151-1.557$ & 0.0002 \\
\hline $\mathrm{CEA}^{\mathrm{C}}$ & - & 1.058 & $0.947-1.181$ & 0.318 \\
\hline CYFRA $21-1^{\mathrm{c}}$ & - & 1.492 & $1.239-1.798$ & $<0.0001$ \\
\hline $\mathrm{SCC}^{\mathrm{C}}$ & - & 1.040 & $0.741-1.461$ & 0.8197 \\
\hline \multicolumn{5}{|c|}{ 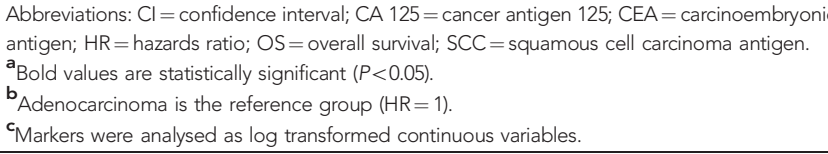 } \\
\hline
\end{tabular}

The prognostic value of LAMC2 was maximised when analysis was restricted to patients of the adenocarcinoma histological subtype ( $N=76$, HR: $1.91,95 \%$ CI: $1.25-2.919, P=0.0028)$ but not in the squamous histological subgroup $(N=16$, HR: 0.941 , 95\% CI: $0.559-1.582, P=0.8177)$. In the same manner, CA 125 was significant within the adenocarcinoma subgroup $(N=76$, HR: $1.405,95 \%$ CI: $1.148-1.72, P=0.001)$, but not in squamous $(N=16$, HR: 1.042 , 95\% CI: $0.503-2.161, P=0.9116)$. CYFRA 21-1 was significant in both subgroups, showing higher significance in the adenocarcinoma group $(N=76, \mathrm{HR}: 1.424$, 95\% CI: $1.107-1.832, P=0.0059)$. CEA was not significant at all, while SCC was borderline significant in the squamous subgroup $(P=0.0447)$.

Finally, LAMC2 levels did not display any major correlation with the rest of the markers measured (Pearson's $r<0.27$ in all cases). In contrast, CA 125 and CYFRA 21-1 were moderately correlated $(r=0.47, P<0.0001)$.

Association of combined sets of parameters with patient OS using multivariate models in the common cohort. The six most significant prognostic parameters (i.e., histology, stage, surgery and markers: LAMC2, CA 125 and CYFRA 21-1) were selected for inclusion in a multivariate prognostic model (Table 3 ). Before that, a clinical model using histology, stage and surgery was constructed for baseline comparison. Also, biomarker models using various combinations of LAMC2, CA 125 and CYFRA 21-1 were built. According to the results, the two-parameter models that included LAMC2 (LAMC2-CA 125 or LAMC2-CYFRA 21-1) outperformed the rest but only the second model was included in the rest of the analysis, as it achieved slightly better fit than the first one (AIC: 288.482 vs 289.182). A model with CA 125 and CYFRA 21-1 showed considerable less prognostic ability (AIC: 294.901).

The mixed five-parameter model had a better fit than the clinical model or the biomarker model, as indicated by lower AIC values (AIC: 286.51 vs 299.480 vs 288.482, respectively). Additionally, the five-parameter model performed significantly better in predicting OS with the estimated concordance indices of $0.81 \mathrm{vs}$ $0.72(P=0.00018)$ vs $0.77(P=0.03726)$, respectively.
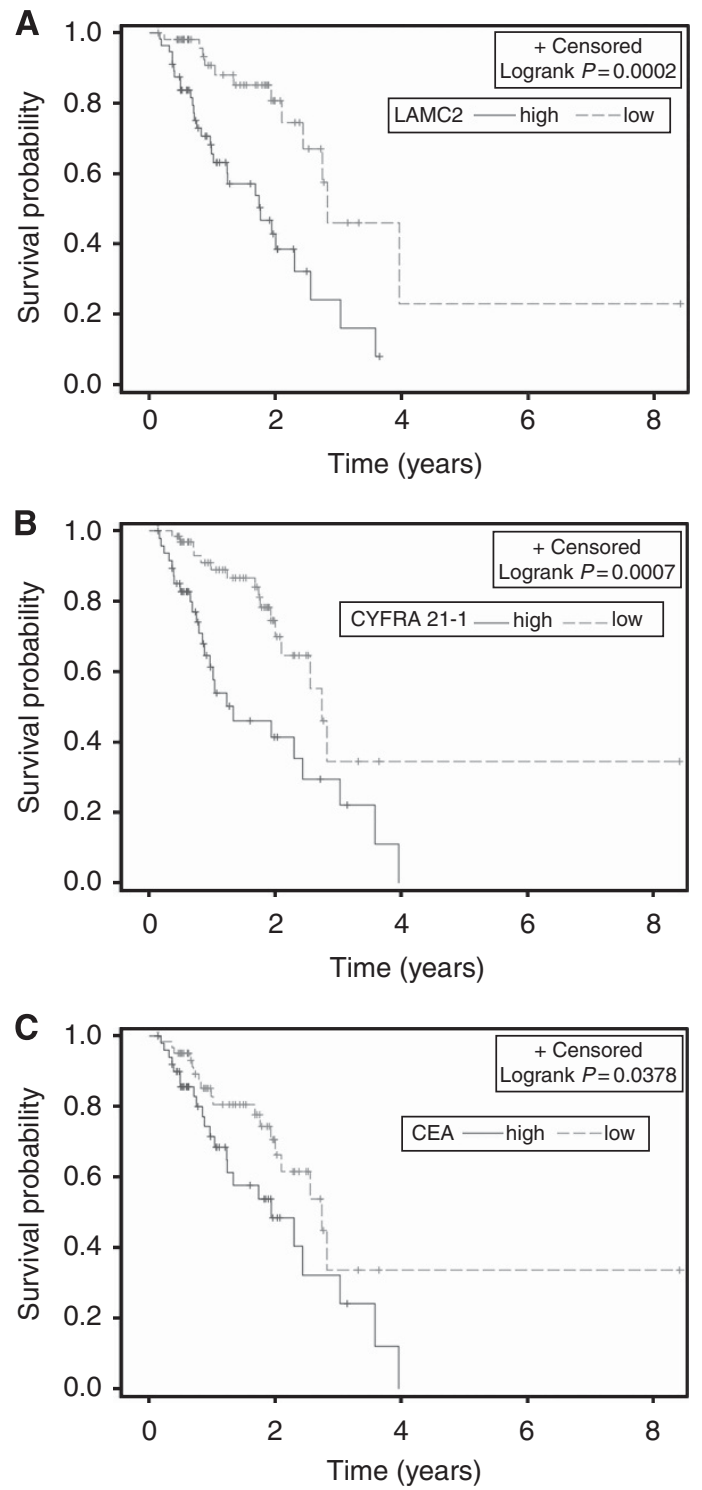

Figure 1. Kaplan-Meier analysis of the association of (A) LAMC2, (B) CYFRA 21-1 and (C) CEA serum levels with OS. Patients were dichotomised (high vs low) based on cut-off values suggested by manufacturer (CA 125, CEA and CYFRA 21-1) or the median value (LAMC2).

Moreover, Kaplan-Meier analysis was used to evaluate twomarker combinations among LAMC2, CA 125, CEA and CYFRA 21-1. Combinations of LAMC2 with CA $125(P=0.0002$, three $\mathrm{df}$ test) or CYFRA 21-1 $(P<0.0001$, three df test $)$ showed statistically significant differences in OS between the four possible expression groups (Figures 2A and B). Cox HRs indicated that they can sufficiently discriminate between the intermediate groups: $\mathrm{HR}_{\mathrm{LAMC} 2(+)} \mathrm{CA} 125(-): 1.99$ and $\mathrm{HR}_{\mathrm{LAMC} 2(-)} \mathrm{CA} 125(+): 3.76$ $(P=0.0001), \quad \operatorname{HR}_{\text {LAMC2 }(+)}$ CYFRA21-1(-) $: 3.08$ and $\operatorname{HR}_{\text {LAMC2 }(-)}$ CYFRA21-1(+):2.44 $(P<0.0001)$ (Tables 4 and 5).

Investigating the prognostic capability of $L A M C 2$ gene expression in an independent cohort. The prognostic potential of $L A M C 2$ gene expression at the mRNA level was examined in an independent cohort consisting of 417 lung adenocarcinoma tumour samples (The Cancer Genome Atlas). LAMC2 mRNA levels displayed a significant prognostic value (log-rank test, $P=0.0014$; HR: $1.89, \mathrm{CI}: 1.27-2.8, P=0.0017)$, thus supporting our earlier findings (Supplementary Table S4). 
Table 3. Multivariate Cox models for OS in the common cohort

\begin{tabular}{|c|c|c|c|c|}
\hline Parameters & Risk group & HR & $95 \% \mathrm{Cl}$ & $P$-value ${ }^{a}$ \\
\hline \multicolumn{5}{|c|}{ Clinical model } \\
\hline Histology ${ }^{b}$ & $\begin{array}{l}\text { Squamous } \\
\text { Other } \\
\text { IIIB-IV } \\
\text { No }\end{array}$ & $\begin{array}{l}2.336 \\
3.223 \\
2.144 \\
1.249\end{array}$ & $\begin{array}{l}0.954-5.718 \\
1.566-6.631 \\
0.748-6.143 \\
0.411-3.794\end{array}$ & $\begin{array}{l}0.1558 \\
0.6949\end{array}$ \\
\hline \multicolumn{5}{|c|}{ Marker model } \\
\hline $\begin{array}{l}\text { LAMC2 }^{c} \\
\text { CYFRA } 21-1^{c}\end{array}$ & - & $\begin{array}{l}1.449 \\
1.387\end{array}$ & $\begin{array}{l}1.098-1.912 \\
1.148-1.676\end{array}$ & $\begin{array}{l}0.0087 \\
0.0007\end{array}$ \\
\hline \multicolumn{5}{|l|}{ Full model } \\
\hline $\begin{array}{l}\text { Stage } \\
\text { Surgery } \\
\text { LAMC2 }^{c} \\
\text { CYFRA } 21-1^{c}\end{array}$ & $\begin{array}{l}\text { Squamous } \\
\text { Other } \\
\text { IIIB-IV } \\
\text { No } \\
- \\
-\end{array}$ & $\begin{array}{l}2.547 \\
2.361 \\
1.655 \\
1.353 \\
1.344 \\
1.398\end{array}$ & $\begin{array}{l}0.991-6.545 \\
1.118-4.984 \\
0.473-5.785 \\
0.372-4.919 \\
1.021-1.769 \\
1.126-1.736\end{array}$ & $\begin{array}{l}0.4304 \\
0.6461 \\
0.0352 \\
0.0024\end{array}$ \\
\hline \multicolumn{5}{|c|}{$\begin{array}{l}\text { Abbreviations: } \mathrm{Cl}=\text { confidence interval; } \mathrm{HR}=\text { hazards ratio; } \mathrm{OS}=\text { overall survival. } \\
\mathrm{a}_{\text {B }} \text { old values are statistically significant }(P<0.05) \text {. } \\
\text { b }_{\text {b }} \text { Adenocarcinoma is the reference group }(H R=1) \text {. } \\
{ }^{c} \text { Markers were analysed as log transformed continuous variables. }\end{array}$} \\
\hline
\end{tabular}

\section{DISCUSSION}

Serological biomarkers have proven to be very important in the management of lung cancer (Stieber and Holdenrieder, 2010). Previous clinical studies in NSCLC exposed the pros and cons of common serum biomarkers for diagnostic applications (Molina et al, 1989; Stieber et al, 1993; Molina et al, 1994; Schalhorn et al, 2001; Molina et al, 2010), while others underlined their value in disease prognosis and therapy monitoring (Barak et al, 2010). From a clinical standpoint, CYFRA 21-1, CEA, CA 125 and SCC still represent the most valuable markers in NSCLC and are primarily used for disease monitoring. However, their prognostic value remains in doubt. Recently, focus has shifted on the discovery of novel prognostic and monitoring markers, as a means to improve clinical management of NSCLC.

Quite a few studies have investigated the expression of Laminin-332 and LAMC2 in human malignancies, either at the mRNA and/or protein level, relating LAMC2 with aggressive disease and unfavourable prognosis. LAMC2 expression has been detected at the invasive front of numerous cancers (e.g, colorectal (Pyke et al, 1995), pancreatic (Tani et al, 1997), gastric (Koshikawa et al, 1999), oral (Ono et al, 1999), esophageal (Yamamoto et al, 2001) and skin (Hamasaki et al, 2011)), including lung adenocarcinoma (Moriya et al, 2001).

Several studies have demonstrated a correlation between LAMC2 expression and tumour invasion and metastasis. According to a study in lung SCC tissues, there seems to be an association between strong LAMC2 staining at the tumour invasive front and the presence of tumour buds-an important feature of cells undergoing epithelial-mesenchymal transition and infiltrative tumours in general (Masuda et al, 2012). Additionally, it has been suggested that LAMC2 expression in cancer cells is elevated during epithelial-mesenchymal transition (Aokage et al, 2011; Zhang et al, 2011) and that it is controlled by regulators of the epithelialmesenchymal transition process, such as ZEB1 and activated $\beta$-catenin (Hlubek et al, 2001; Sanchez-Tillo et al, 2011). This direct association of LAMC2 with epithelial-mesenchymal transition and its positive effect on metastasis is being favoured by a recent study in lung adenocarcinoma (Moon et al, 2015). Another recent article has even proposed a direct interaction of LAMC2 with epidermal growth factor receptor in anaplastic
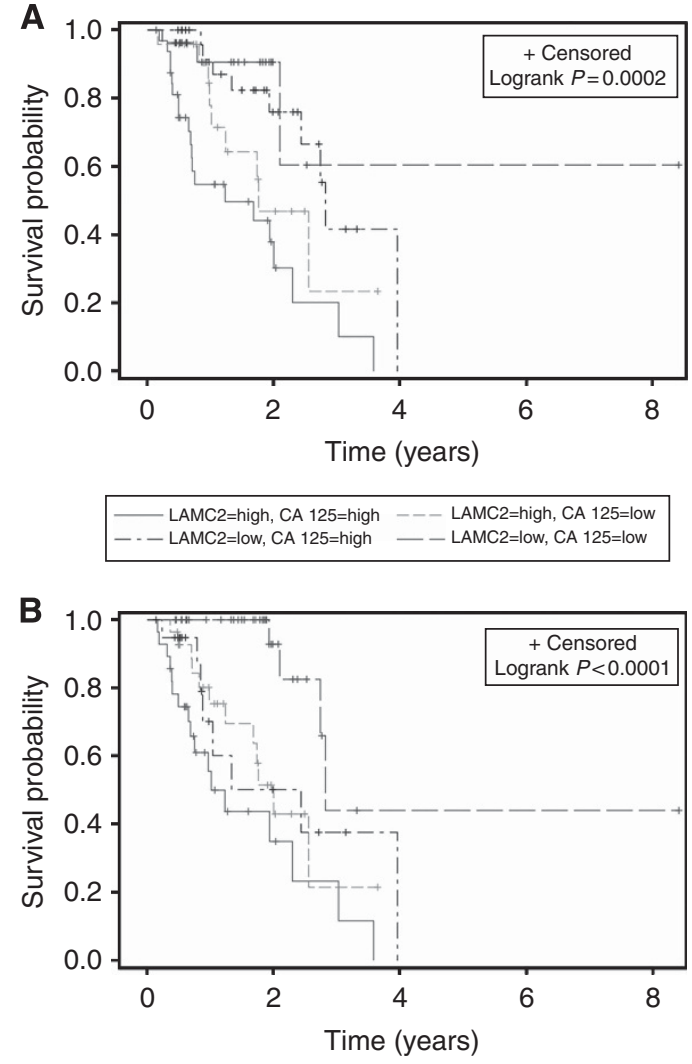

- LAMC2=high, CYFRA 21-1=high --- LAMC2=high, CYFRA 21-1=low
--- LAMC2=low, CYFRA 21-1=high - - LAMC2=low, CYFRA 21-1=low

Figure 2. Kaplan-Meier analysis of the association of (A) LAMC2-CA 125 and (B) LAMC2-CYFRA 21-1 combinations with OS. Patients were dichotomised (high vs low) based on cut-off values suggested by manufacturer (CA 125 and CYFRA 21-1) or the median value (LAMC2).

thyroid carcinoma cells and further suggested that it could be a target for therapeutic intervention (Garg et al, 2014).

Concerning the presence of LAMC2 in circulation, initial studies have shown that Laminin-332 can be secreted by epithelial cells in the extracellular matrix and enzymatically processed by matrix metalloproteinases, thus resulting in the release of LAMC2 fragments from the complex (Giannelli et al, 1997; Koshikawa et al, 2000). According to later studies, this release of LAMC2 fragments could be detected in the bloodstream, while in malignant conditions it seems to be associated with the aggressiveness of the disease (Katayama et al, 2003; Katayama et al, 2005; Kuratomi et al, 2008).

To our knowledge, this is the first clinical evaluation of LAMC2 as a serum prognostic NSCLC marker, either on its own or in combination with other established prognostic modalities. Initially, LAMC2 was analysed in the full cohort and displayed significant prognostic value for OS (HR: 1.607, $P<0.0001$ ). In addition, Kaplan-Meier analysis revealed significantly higher median OS for patients with low levels of LAMC2 compared with patients with high levels of LAMC2 (2.82 years vs 1.68 years, respectively) (Supplementary Figure S1). Subsequently, LAMC2 and other four tumour markers were analysed in a common cohort of 112 samples. LAMC2 maintained its prognostic ability, especially in adenocarcinoma patients $(N=76$, HR: $1.91, P=0.0028)$. CA 125 and CYFRA 21-1 also showed great potential for prognosis and were used together with LAMC2 and clinical variables to construct multivariate prognostic models.

A constructed multivariate model combining LAMC2 and CYFRA 21-1 levels, histological subtypes, tumour staging and 
Table 4. Estimated overall survival probability according to LAMC2 (cut-off: $109.55 \mathrm{ng} \mathrm{ml}^{-1}$ ) and CA 125 (cut-off: $35 \mathrm{U} \mathrm{ml}^{-1}$ ) status (high: (+), low: $(-))$. Cox Hazard Ratios are also included

\begin{tabular}{|l|c|c|c|c|}
\hline Overall survival & $\begin{array}{c}\text { LAMC2 }(-) \text { CA } \\
\mathbf{1 2 5}(-)(\mathbf{N}=\mathbf{2 8})\end{array}$ & $\begin{array}{c}\text { LAMC2 }_{(+)} \text {CA } \\
\mathbf{1 2 5}(-)(\mathbf{N}=\mathbf{2 4})\end{array}$ & $\begin{array}{c}\text { LAMC2 }_{(-)} \text {CA } \\
\mathbf{1 2 5}_{(+)}(\mathbf{N}=\mathbf{2 8})\end{array}$ & $\begin{array}{c}\text { LAMC2 }_{(+)} \text {CA } \\
\mathbf{1 2 5}(+)\end{array}$ \\
\hline 1 Year & $90.6 \%$ & $78.0 \%$ & $91.3 \%$ & $54.7 \%$ \\
\hline 2 Years & $90.6 \%$ & $46.9 \%$ & $76.0 \%$ & $30.3 \%$ \\
\hline 3 Years & $60.4 \%$ & $23.4 \%$ & $41.6 \%$ & $20.2 \%$ \\
\hline Hazard ratio & 1.00 & 1.99 & 3.76 & 7.47 \\
\hline Abbreviations: CA 125, cancer antigen 125. \\
\hline
\end{tabular}

Table 5. Estimated overall survival probability according to LAMC2 (cut-off: $109.55 \mathrm{ng} \mathrm{ml}^{-1}$ ) and CYFRA 21-1 (cut-off: $2.08 \mathrm{ng} \mathrm{ml}^{-1}$ ) status (high: $(+)$, low: $(-)$ ). Cox hazard ratios are also included

\begin{tabular}{|c|c|c|c|c|}
\hline Overall survival & $\begin{array}{c}\text { LAMC2 }(-) \text { CYFRA } \\
21-1(-)(N=36)\end{array}$ & $\begin{array}{c}\text { LAMC2 }_{(+)} \text {CYFRA } \\
21-1(-)(N=28)\end{array}$ & $\begin{array}{c}\text { LAMC2 }(-) \text { CYFRA } \\
21-1_{(+)}(N=20)\end{array}$ & $\begin{array}{l}\text { LAMC }_{(+)} \text {CYFRA } \\
21-1_{(+)}(N=28)\end{array}$ \\
\hline 1 Year & $100 \%$ & $75.3 \%$ & $70.2 \%$ & $55.5 \%$ \\
\hline 2 Years & $92.9 \%$ & $42.9 \%$ & $50.1 \%$ & $35.0 \%$ \\
\hline 3 Years & $44.0 \%$ & $21.5 \%$ & $37.6 \%$ & $23.3 \%$ \\
\hline Hazard ratio & 1.00 & 3.08 & 2.44 & 7.52 \\
\hline
\end{tabular}

surgery status (five-parameter model) was compared with a clinical model (including histology, stage and surgery), as well a twoparameter model consisting of LAMC2, CYFRA 21-1 (Table 3). Our data suggested that addition of LAMC2 and CYFRA21-1 in the prognostic model has a significant prognostic potential (concordance index: 0.81 vs 0.72 vs 0.77 ), also underlined by the calculated cross-validation concordance indices $(0.79$ vs 0.71 vs 0.76). Moreover, Kaplan-Meier analyses of several two-marker models suggested that combinations of LAMC2 with CA 125 or CYFRA 21-1 could discriminate between OS better than the rest of the marker combinations (log-rank test, $P=0.0002$ and $P<0.0001$, respectively) (Figures $2 \mathrm{~A}$ and $\mathrm{B}$ ), enabling stratification of patients into clear risk groups (Tables 4 and 5).

To further support our findings, evidence was sought in the The Cancer Genome Atlas portal. LAMC2 mRNA levels revealed the marker's prognostic ability (log-rank test, $P=0.0014$; HR: $1.88, \mathrm{CI}$ : $1.27-2.80, P=0.0017$ ), thus confirming indirectly, and in an independent cohort, the prognostic potential of the marker (Supplementary Table S4).

In summary, our retrospective study reveals an important new role for LAMC2 as a novel serum prognostic marker for NSCLC, especially for lung adenocarcinoma. Along with LAMC2, we also evaluated the prognostic performance of four known lung markers (i.e., CA 125, CEA, CYFRA 21-1 and SCC). Our data confirmed the association of the aforementioned markers with poor prognosis. Results for some of the markers (e.g., SCC) were inconclusive since non-adenocarcinoma samples were underrepresented. We found that the combination of LAMC2 with CYFRA 21-1 displays significant prognostic information. Furthermore, when these two markers were combined with some established clinicopathological parameters (i.e., histology, stage and surgery) the prognostic potential was maximised. Our study is limited by the small number of patients and the absence of additional validation data sets. Additionally, The Cancer Genome Atlas data have their own constraints as well, with more striking one being the relatively short follow-up period (median follow-up: 0.64 years, mean follow-up: 1.43 years). However, our data clearly highlight the potential of LAMC2 serum levels for NSCLC prognosis, as well as its ability to complement and enhance the performance of established clinical and biochemical markers of the disease. Further evaluation of LAMC2 and rest of the markers (alone or in combination) in larger independent patient cohorts is necessary. In addition, the assessment of the aforementioned molecules' predictive value in trial settings is much needed, in order to accomplish an important milestone towards individualised therapy of lung cancer.

\section{ACKNOWLEDGEMENTS}

We thank 'The Cancer Genome Atlas' (TCGA) portal for providing data for lung cancer adenocarcinoma patients.

\section{CONFLICT OF INTEREST}

The authors declare no conflict of interest.

\section{REFERENCES}

Akaike H (1974) A new look at the statistical model identification. IEEE Trans Automat Control 19: 716-723.

Ando S, Kimura H, Iwai N, Yamamoto N, Iida T (2003) Positive reactions for both Cyfra21-1 and CA125 indicate worst prognosis in non-small cell lung cancer. Anticancer Res 23: 2869-2874.

Aokage K, Ishii G, Ohtaki Y, Yamaguchi Y, Hishida T, Yoshida J, Nishimura M, Nagai K, Ochiai A (2011) Dynamic molecular changes associated with epithelial-mesenchymal transition and subsequent mesenchymal-epithelial transition in the early phase of metastatic tumor formation. Int J Cancer 128: $1585-1595$.

Arrieta O, Saavedra-Perez D, Kuri R, Aviles-Salas A, Martinez L, MendozaPosada D, Castillo P, Astorga A, Guzman E, De la Garza J (2009) Brain metastasis development and poor survival associated with carcinoembryonic antigen (CEA) level in advanced non-small cell lung cancer: a prospective analysis. BMC Cancer 9: 119.

Barak V, Goike H, Panaretakis KW, Einarsson R (2004) Clinical utility of cytokeratins as tumor markers. Clin Biochem 37: 529-540.

Barak V, Holdenrieder S, Nisman B, Stieber P (2010) Relevance of circulating biomarkers for the therapy monitoring and follow-up investigations in patients with non-small cell lung cancer. Cancer Biomark 6: 191-196.

Chan A, Prassas I, Dimitromanolakis A, Brand RE, Serra S, Diamandis EP, Blasutig IM (2014) Validation of biomarkers that complement CA19.9 in detecting early pancreatic cancer. Clin Cancer Res 20: 5787-5795.

Cox DR (1972) Regression models and life-tables. J R Stat Soc 34: $187-220$. 
Diez M, Torres A, Maestro ML, Ortega MD, Gomez A, Pollan M, Lopez JA, Picardo A, Hernando F, Balibrea JL (1996) Prediction of survival and recurrence by serum and cytosolic levels of CEA, CA125 and SCC antigens in resectable non-small-cell lung cancer. $\mathrm{Br} J$ Cancer 73: 1248-1254.

Ferrigno D, Buccheri G, Giordano C (2003) Neuron-specific enolase is an effective tumour marker in non-small cell lung cancer (NSCLC). Lung Cancer 41: 311-320.

Flehinger BJ, Kimmel M, Melamed MR (1992) The effect of surgical treatment on survival from early lung cancer. Implications for screening. Chest 101: 1013-1018.

Fukushima Y, Ohnishi T, Arita N, Hayakawa T, Sekiguchi K (1998) Integrin alpha3beta1-mediated interaction with laminin-5 stimulates adhesion, migration and invasion of malignant glioma cells. Int J Cancer 76: 63-72.

Garg M, Kanojia D, Okamoto R, Jain S, Madan V, Chien W, Sampath A, Ding LW, Xuan M, Said JW, Doan NB, Liu LZ, Yang H, Gery S, Braunstein GD, Koeffler HP (2014) Laminin-5 gamma-2 (LAMC2) is highly expressed in anaplastic thyroid carcinoma and is associated with tumor progression, migration, and invasion by modulating signaling of EGFR. J Clin Endocrinol Metab 99: E62-E72.

Gasparoni A, Della Casa M, Milillo L, Lorenzini G, Rubini C, Urso R, Lo Muzio L (2007) Prognostic value of differential expression of Laminin5 gamma2 in oral squamous cell carcinomas: correlation with survival. Oncol Rep 18: 793-800.

Giannelli G, Falk-Marzillier J, Schiraldi O, Stetler-Stevenson WG, Quaranta V (1997) Induction of cell migration by matrix metalloprotease-2 cleavage of laminin-5. Science 277: 225-228.

Govindan R, Bogart J, Vokes EE (2008) Locally advanced non-small cell lung cancer: the past, present, and future. J Thorac Oncol 3: 917-928.

Hamasaki H, Koga K, Aoki M, Hamasaki M, Koshikawa N, Seiki M, Iwasaki H, Nakayama J, Nabeshima K (2011) Expression of laminin 5-gamma2 chain in cutaneous squamous cell carcinoma and its role in tumour invasion. $\mathrm{Br} J$ Cancer 105: 824-832.

Harrell Jr. FE, Califf RM, Pryor DB, Lee KL, Rosati RA (1982) Evaluating the yield of medical tests. JAMA 247: 2543-2546.

Hatzakis KD, Froudarakis ME, Bouros D, Tzanakis N, Karkavitsas N, Siafakas NM (2002) Prognostic value of serum tumor markers in patients with lung cancer. Respiration 69: 25-29.

Hirashima T, Takada M, Komiya T, Nitta T, Masashi K, Masuda N, Matui K, Kikui M, Yasumitsu T, Kawase I (1998) Prognostic significance of CYFRA 21-1 in non-small cell lung cancer. Anticancer Res 18: 4713-4716.

Hlubek F, Jung A, Kotzor N, Kirchner T, Brabletz T (2001) Expression of the invasion factor laminin gamma 2 in colorectal carcinomas is regulated by beta-catenin. Cancer Res 61: 8089-8093.

Hohenester E, Yurchenco PD (2013) Laminins in basement membrane assembly. Cell Adh Migr 7: 56-63.

Holdenrieder S, Nagel D, Stieber P (2010) Estimation of prognosis by circulating biomarkers in patients with non-small cell lung cancer. Cancer Biomark 6: 179-190.

Jemal A, Bray F, Center MM, Ferlay J, Ward E, Forman D (2011) Global cancer statistics. CA Cancer J Clin 61: 69-90.

Kaplan EL, Meier P (1958) Nonparametric estimation from incomplete observations. J Am Stat Assoc 53: 457-481.

Katayama M, Funakoshi A, Sumii T, Sanzen N, Sekiguchi K (2005) Laminin gamma2-chain fragment circulating level increases in patients with metastatic pancreatic ductal cell adenocarcinomas. Cancer Lett 225: 167-176.

Katayama M, Sanzen N, Funakoshi A, Sekiguchi K (2003) Laminin gamma2chain fragment in the circulation: a prognostic indicator of epithelial tumor invasion. Cancer Res 63: 222-229.

Kosanam H, Prassas I, Chrystoja CC, Soleas I, Chan A, Dimitromanolakis A, Blasutig IM, Ruckert F, Gruetzmann R, Pilarsky C, Maekawa M, Brand R, Diamandis EP (2013) Laminin, gamma 2 (LAMC2): a promising new putative pancreatic cancer biomarker identified by proteomic analysis of pancreatic adenocarcinoma tissues. Mol Cell Proteomics 12: 2820-2832.

Koshikawa N, Giannelli G, Cirulli V, Miyazaki K, Quaranta V (2000) Role of cell surface metalloprotease MT1-MMP in epithelial cell migration over laminin-5. J Cell Biol 148: 615-624.

Koshikawa N, Moriyama K, Takamura H, Mizushima H, Nagashima Y, Yanoma S, Miyazaki K (1999) Overexpression of laminin gamma2 chain monomer in invading gastric carcinoma cells. Cancer Res 59: 5596-5601.

Kulpa J, Wojcik E, Reinfuss M, Kolodziejski L (2002) Carcinoembryonic antigen, squamous cell carcinoma antigen, CYFRA 21-1, and neuron-specific enolase in squamous cell lung cancer patients. Clin Chem 48: 1931-1937.
Kuratomi Y, Sato S, Monji M, Shimazu R, Tanaka G, Yokogawa K, Inoue A, Inokuchi A, Katayama M (2008) Serum concentrations of laminin gamma2 fragments in patients with head and neck squamous cell carcinoma. Head Neck 30: 1058-1063.

Ma J, Gao M, Lu Y, Feng X, Zhang J, Lin D, Xiao T, Hu Z, Yuan J, Su K, Shipley J, Xue J, Gao Y (2006) Gain of 1q25-32, 12q23-24.3, and 17q12-22 facilitates tumorigenesis and progression of human squamous cell lung cancer. J Pathol 210: 205-213.

Maatta M, Soini Y, Paakko P, Salo S, Tryggvason K, Autio-Harmainen H (1999) Expression of the laminin gamma2 chain in different histological types of lung carcinoma. A study by immunohistochemistry and in situ hybridization. J Pathol 188: 361-368.

Manda R, Kohno T, Niki T, Yamada T, Takenoshita S, Kuwano H, Yokota J (2000) Differential expression of the LAMB3 and LAMC2 genes between small cell and non-small cell lung carcinomas. Biochem Biophys Res Commun 275: 440-445.

Margolis ML, Hyzy JB, Schenken LL, Schepart BS (1994) Serum tumor markers in non-small cell lung cancer. A comparative analysis. Cancer 73: 605-609.

Masuda R, Kijima H, Imamura N, Aruga N, Nakazato K, Oiwa K, Nakano T, Watanabe H, Ikoma Y, Tanaka M, Inokuchi S, Iwazaki M (2012) Laminin5 gamma2 chain expression is associated with tumor cell invasiveness and prognosis of lung squamous cell carcinoma. Biomed Res 33: 309-317.

Molina R, Agusti C, Mane JM, Filella X, Jo J, Joseph J, Gimenez N, Estape J, Ballesta AM (1994) CYFRA 21-1 in lung cancer: comparison with CEA, CA 125, SCC and NSE serum levels. Int J Biol Markers 9: 96-101.

Molina R, Filella X, Auge JM, Fuentes R, Bover I, Rifa J, Moreno V, Canals E, Vinolas N, Marquez A, Barreiro E, Borras J, Viladiu P (2003) Tumor markers (CEA, CA 125, CYFRA 21-1, SCC and NSE) in patients with nonsmall cell lung cancer as an aid in histological diagnosis and prognosis. Comparison with the main clinical and pathological prognostic factors. Tumour Biol 24: 209-218.

Molina R, Holdenrieder S, Auge JM, Schalhorn A, Hatz R, Stieber P (2010) Diagnostic relevance of circulating biomarkers in patients with lung cancer. Cancer Biomark 6: 163-178.

Molina R, Santabarbara P, Filella X, Mengual P, Ballesta AM, Balague A (1989) Relationship of CA 125 and CA 19.9 with lung carcinoma histological subtype: preliminary study. Int J Biol Markers 4: 215-220.

Moon YW, Rao G, Kim JJ, Shim HS, Park KS, An SS, Kim B, Steeg PS, Sarfaraz S, Changwoo Lee L, Voeller D, Choi EY, Luo J, Palmieri D, Chung HC, Kim JH, Wang Y, Giaccone G (2015) LAMC2 enhances the metastatic potential of lung adenocarcinoma. Cell Death Differ 22: 1341-1352.

Moriya Y, Niki T, Yamada T, Matsuno Y, Kondo H, Hirohashi S (2001) Increased expression of laminin-5 and its prognostic significance in lung adenocarcinomas of small size. An immunohistochemical analysis of 102 cases. Cancer 91: 1129-1141.

Moro D, Villemain D, Vuillez JP, Delord CA, Brambilla C (1995) CEA, CYFRA21-1 and SCC in non-small cell lung cancer. Lung Cancer 13: 169-176.

Mountain CF (2000) The international system for staging lung cancer. Semin Surg Oncol 18: 106-115.

Muley T, Dienemann H, Ebert W (2004) CYFRA 21-1 and CEA are independent prognostic factors in 153 operated stage I NSCLC patients. Anticancer Res 24: 1953-1956.

Niklinski J, Furman M, Laudanski J, Kozlowski M (1992) Prognostic value of pretreatment CEA, SCC-Ag and CA 19-9 levels in sera of patients with non-small cell lung cancer. Eur J Cancer Prev 1: 401-406.

Okada M, Nishio W, Sakamoto T, Uchino K, Yuki T, Nakagawa A, Tsubota N (2004) Prognostic significance of perioperative serum carcinoembryonic antigen in non-small cell lung cancer: analysis of 1,000 consecutive resections for clinical stage I disease. Ann Thorac Surg 78: 216-221.

Ono Y, Nakanishi Y, Ino Y, Niki T, Yamada T, Yoshimura K, Saikawa M, Nakajima T, Hirohashi S (1999) Clinicopathologic significance of laminin5 gamma2 chain expression in squamous cell carcinoma of the tongue: immunohistochemical analysis of 67 lesions. Cancer 85: 2315-2321.

Pujol JL, Boher JM, Grenier J, Quantin X (2001) Cyfra 21-1, neuron specific enolase and prognosis of non-small cell lung cancer: prospective study in 621 patients. Lung Cancer 31: 221-231.

Pujol JL, Grenier J, Daures JP, Daver A, Pujol H, Michel FB (1993) Serum fragment of cytokeratin subunit 19 measured by CYFRA 21-1 immunoradiometric assay as a marker of lung cancer. Cancer Res 53: 61-66.

Pyke C, Salo S, Ralfkiaer E, Romer J, Dano K, Tryggvason K (1995) Laminin-5 is a marker of invading cancer cells in some human carcinomas and is coexpressed with the receptor for urokinase plasminogen activator in 
budding cancer cells in colon adenocarcinomas. Cancer Res 55: 4132-4139.

Quinn FA (2005) Architect $(2000 ®$ and $12000 ® S R$ Analyzers. In Wild D (ed) The Immunoassay Handbook. 3rd edn pp 406-411. Elsevier Ltd: Amsterdam.

Rousselle P, Lunstrum GP, Keene DR, Burgeson RE (1991) Kalinin: an epithelium-specific basement membrane adhesion molecule that is a component of anchoring filaments. J Cell Biol 114: 567-576.

Sanchez-Tillo E, de Barrios O, Siles L, Cuatrecasas M, Castells A, Postigo A (2011) beta-catenin/TCF4 complex induces the epithelial-to-mesenchymal transition (EMT)-activator ZEB1 to regulate tumor invasiveness. Proc Natl Acad Sci USA 108: 19204-19209.

Sathyanarayana UG, Toyooka S, Padar A, Takahashi T, Brambilla E, Minna JD, Gazdar AF (2003) Epigenetic inactivation of laminin-5-encoding genes in lung cancers. Clin Cancer Res 9: 2665-2672.

Schalhorn A, Fuerst H, Stieber P (2001) Tumor markers in lung cancer. J Lab Med 25: 353-361.

Siegel R, Naishadham D, Jemal A (2013) Cancer statistics, 2013. CA Cancer J Clin 63: 11-30.

Singhal S, Vachani A, Antin-Ozerkis D, Kaiser LR, Albelda SM (2005) Prognostic implications of cell cycle, apoptosis, and angiogenesis biomarkers in nonsmall cell lung cancer: a review. Clin Cancer Res 11: 3974-3986.

Soini Y, Maatta M, Salo S, Tryggvason K, Autio-Harmainen H (1996) Expression of the laminin gamma 2 chain in pancreatic adenocarcinoma. $J$ Pathol 180: 290-294.

Sordat I, Bosman FT, Dorta G, Rousselle P, Aberdam D, Blum AL, Sordat B (1998) Differential expression of laminin-5 subunits and integrin receptors in human colorectal neoplasia. J Pathol 185: 44-52.

Stieber P, Hasholzner U, Bodenmuller H, Nagel D, Sunder-Plassmann L, Dienemann H, Meier W, Fateh-Moghadam A (1993) CYFRA 21-1. A new marker in lung cancer. Cancer 72: 707-713.
Stieber P, Holdenrieder S (2010) Lung cancer biomarkers - Where we are and what we need. Cancer Biomark 6: 221-224.

Takahashi Y, Ishii G, Taira T, Fujii S, Yanagi S, Hishida T, Yoshida J, Nishimura M, Nomori H, Nagai K, Ochiai A (2011) Fibrous stroma is associated with poorer prognosis in lung squamous cell carcinoma patients. J Thorac Oncol 6: 1460-1467.

Tani T, Lumme A, Linnala A, Kivilaakso E, Kiviluoto T, Burgeson RE, Kangas L, Leivo I, Virtanen I (1997) Pancreatic carcinomas deposit laminin-5, preferably adhere to laminin-5, and migrate on the newly deposited basement membrane. Am J Pathol 151: 1289-1302.

Timpl R, Brown JC (1994) The laminins. Matrix Biol 14: 275-281.

Travis WD, Brambilla E, Muller-Hermelink HK, Harris CC (2004) Pathology and Genetics of Tumours of the Lung, Pleura, Thymus and Heart. IARC Press: Lyon.

Vassilakopoulos T, Troupis T, Sotiropoulou C, Zacharatos P, Katsaounou P, Parthenis D, Noussia O, Troupis G, Papiris S, Kittas C, Roussos C, Zakynthinos S, Gorgoulis V (2001) Diagnostic and prognostic significance of squamous cell carcinoma antigen in non-small cell lung cancer. Lung Cancer 32: 137-144.

Yamamoto H, Itoh F, Iku S, Hosokawa M, Imai K (2001) Expression of the gamma(2) chain of laminin-5 at the invasive front is associated with recurrence and poor prognosis in human esophageal squamous cell carcinoma. Clin Cancer Res 7: 896-900.

Zhang Y, Yan W, Chen X (2011) Mutant p53 disrupts MCF-10A cell polarity in three-dimensional culture via epithelial-to-mesenchymal transitions. $J$ Biol Chem 286: 16218-16228.

This work is published under the standard license to publish agreement. After 12 months the work will become freely available and the license terms will switch to a Creative Commons AttributionNonCommercial-Share Alike 4.0 Unported License

Supplementary Information accompanies this paper on British Journal of Cancer website (http://www.nature.com/bjc) 